\title{
HEPATITE CRÔNICA POR VIRUS C Parte 2. Tratamento
}

\author{
Vinício Paride CONTE*
}

RESUMO - São revistos aspectos relativos às drogas utilizadas, suas dosagens, tempo de duração dos tratamentos, as diferentes respostas terapêuticas obtidas, segundo os vários tipos de doença e de doentes estudados, assim como os fatores que podem modificar os resultados obtidos.

DESCRITORES - Hepatite C, terapia. Interferon. Ribavirina. Amantadina. Vacinas.

A hepatite por vírus $\mathrm{C}$ (HVC) é a principal causa de doença hepática que leva à cirrose e ao carcinoma hepatocelular.

Nos EUA cerca de 3,5 a 4 milhões de indivíduos estão infectados pelo vírus ${ }^{(1)}$. Cerca de $80 \%$ deles tornam-se doentes crônicos e $20 \%$ evoluem para a cirrose, sendo a metade eventualmente passível de desenvolver insuficiência hepática aguda ou hepatocarcinoma ${ }^{(26,29,56)}$.

No Peru, SILVA et al. ${ }^{(47)}$, encontraram presença de anticorpos anti-HVC (Ac anti-HVC) em 17\% de 64 pacientes com doença hepática crônica não-alcoólica.

GARASSINI et al. ${ }^{(19)}$, na Venezuela, detectaram positividade para Ac anti-HVC, utilizando técnica ELISA comercial, nos seguintes grupos estudados: 102 pessoas da área da saúde (1,96\%), 16 pacientes em hemodiálise crônica (33\%), 20 pacientes aidéticos $(35,4 \%), 10$ pacientes com HbsAg negativos (70\%); 25 pacientes com cirrose hepática (48\%) e 2 pacientes com hepatocarcinoma (50\%).

FINDOR et al. ${ }^{(17)}$, na Argentina, em diferentes hepatopatias crônicas, em que foram descartadas etiologias medicamentosa, por vírus B, alcoolismo, alterações metabólicas e colangite esclerosante primária, determinaram a prevalência de Ac anti-HVC IgG, com a técnica ELISA e obtiveram os seguintes resultados: grupo A 94,2\% (35 casos); grupo B 38,4\% (39 casos); grupo C 21,6\% (37 casos); grupo D 3,22\% (31 casos) e grupo E 33,3\% (6 casos). Concluem que a detecção de Ac anti-HVC IgG é importante para melhor caracterizar as hepatites não A-não B com antecedentes parenterais ou de transfusões, parecendo que a etiologia viral C da hepatite é também freqüente nos pacientes sem antecedentes parenterais. Ainda, os autores acreditam que na cirrose biliar primária (CBP), o vírus da hepatite $\mathrm{C}$ é raramente encontrado, ao contrário do que pode ocorrer na síndrome intermediária, onde os casos positivos são mais freqüentes.

Outro aspecto duvidoso surgiu em relação aos casos de hepatite crônica ativa (HCA) com componente imunológico apreciável. Nestes, o anticorpo anti-HVC IgG foi também detectado. Seriam casos de HVC verdadeiros ou decorrentes de erros da metodologia imune empregada. Existem evidências de que a intervenção terapêutica pode melhorar o prognóstico e as complicações da doença.

O tratamento ideal ainda não foi estabelecido, sendo o interferon (INF) o único aprovado, apesar de seus baixos índices de resposta e acentuados efeitos colaterais, podendo no entanto, mudar o curso evolutivo da doença para melhor.

Existem três classes de INFs: alfa/beta/gama, imunológica, estrutural e antigenicamente diferentes entre si. O alfa é produzido por monócitos e células B frente a infeções virais e estímulos antigênicos. $\mathrm{O}$ beta é produzido por fibroblastos e é semelhante ao anterior, formando o tipo 1 . O gama tem estrutura e loco genético diferente dos dois anteriores e se

* Professor Associado do Departamento de Gastroenterologia da Faculdade de Medicina da Universidade de São Paulo.

Endereço para correspondência: Dr. Vinício Paride Conte - Av. Brigadeiro Faria Lima, 1993 - Cj. 21 - 01451-001 - São Paulo, SP. 
constitui no tipo 2. É formado pelas células T e NK (natural killer), sendo seu efeito mais imunemodulador do que anti-viral ${ }^{(35)}$.

Os INFs pertencem à superfamília das citoquinas e modulam a atividade de vários componentes do sistema imune, aumentando a habilidade dos organismos na luta contra as infecções bacterianas, parasitárias e virais. Constituem-se, portanto, em famílias de proteínas responsáveis por efeitos antivirais, antiproliferativos e imunemoduladores por excelência. Sem nenhuma dúvida, eles são as primeiras linhas de defesa contra essas infeções, mesmo antes de uma completa mobilização do sistema imune reativo. No entanto, os altos índices de não-respondedores e de reativação da doença entre os portadores de $\mathrm{HVC}$, antes mesmo do término do tratamento programado, levanta o problema da formação de anticorpos anti-INF, nestes pacientes ${ }^{(30)}$.

Outra causa de recaída durante o tratamento é a exacerbação dos processos autoimunes ${ }^{(48)}$. Esses efeitos imunes produzidos pelos INFs são complexos. Os interferons gama são os mais imunemoduladores e menos antivirais, quando comparados aos alfa e beta. Induzem a reações de histocompatibilidade (HLA classe I e II) envolvendo vários tipos celulares. São importantes na cascata da linfocina (interleucina 1 e 2, fator de necrose tumoral). Os alfa e os beta modulam a síntese de imuneglobulinas de maneira positiva e negativa. Podem induzir à reorganização das células $\mathrm{T}$ receptoras e, portanto, à maturação das células T citotóxicas.

Os INFs na dose de 3 a 6 milhões de unidades por dia, via subcutânea ou intramuscular, três vezes por semana, produzem efeitos precoces e tardios. Dentre os primeiros destaca-se (em 60\%-70\% dos casos) a síndrome gripal (febre de 38 a $40{ }^{\circ} \mathrm{C}$ que aparece 4-6 horas após a injeção, calafrios, mialgias, cefaléia e, menos freqüentemente, artralgias). O paracetamol $500 \mathrm{mg}$, ingerido algumas horas antes, pode bloquear esses efeitos colaterais. Outros efeitos colaterais podem ser observados (em cerca de $20 \%$ dos casos), como anorexia e náuseas. É de bom alvitre hospitalizar os pacientes durante as primeiras 24 horas para melhor avaliar e combater esses efeitos colaterais da primeira dose. Nas doses subseqüentes eles são decrescentes, desde que os intervalos entre as injeções não ultrapassem 3 dias. Dentre os efeitos tardios, temos os sistêmicos, os hematológicos, os infecciosos, os autoimunes e os psiquiátricos.

1. Sistêmicos: fadiga (muito freqüente), mialgia, febrícula, cefaléia, anorexia, perda de peso. Perda de cabelos e da libido são mais raros e reversíveis.

2. Hematológicos: leucopenia, plaquetopenia em $69 \%$ e $42 \%$ dos casos, respectivamente ${ }^{(12)}$, mais freqüentes nos casos de cirrose e de hiperesplenismo.

3. Infecciosos: de natureza bacteriana, principalmente urinária, sinusite e bronquite são os mais importantes. Essas infecções quando acometem pacientes com cirrose descompensada, devem ser prontamente avaliadas e corrigidas com antibióticos adequados.
4. Autoimunes: os INFs podem ocasionar produção de vários anticorpos e, assim, determinar doenças clínicas autoimunes, como tiroidites com destruição da glândula, e hipotiroidismo ${ }^{(42)}$. Os casos de hipertiroidismo são mais $\operatorname{raros}^{(9)}$.

5. Psiquiátricos: irritabilidade, ansiedade, depressão, delírio. Não se conhecem os mecanismos fisiopatológicos envolvidos. Certos medicamentos podem ser benéficos nestas situações particulares, como por exemplo, a clorpropamida.

A maioria dos estudos sobre tratamento das hepatites virais foi feita com INF-alfa.

Devido aos altos índices de não-respondedores e ao grande número de recaídas e recidivas, várias tentativas terapêuticas têm sido propostas no sentido de contornar esses óbices. Assim, 30\% a $65 \%$ dos pacientes com HVC têm normalização da alanina aminotransferase (ALT) 24 semanas após uso de INF, inclusive com melhora histológica e funcional do fígado ${ }^{(38)}$.

POLACHON et al. ${ }^{(36)}$, em pacientes que receberam 3 milhões de unidades 3 vezes por semana, durante 6 meses e que não responderam, instituíram: a) 10 milhões de unidades 3 vezes por semana, durante 2 meses e a seguir 6 milhões de unidades 3 vezes por semana, mais 4 meses; b) 6 milhões de unidades 3 vezes por semana durante 6 meses. Obtiveram $44,4 \%$ de resposta positiva nesse segundo grupo não significante em comparação com o grupo inicial.

BODENHEIMER et al. ${ }^{(4)}$ utilizaram ribavirina $-1200 \mathrm{mg}$ por dia - via oral, durante 36 semanas, sem resultados apreciáveis, ou seja, nenhum paciente manteve níveis normais de ALT após a parada do fármaco, nem houve decréscimo dos níveis de HVC RNA durante o estudo.

SMITH $^{(49)}$ utilizou amantadina - $200 \mathrm{mg}$ por dia — durante 6 meses, em 22 pacientes que não responderam a tratamento prévio com INF-alfa-2b, obtendo bons resultados bioquímicos e virológicos (HVC RNA com PCR negativo 6 meses após interrupção do tratamento).

BELLOBUONO et al. ${ }^{(2)}$ associaram ribavirina e INF-alfa, em casos inicialmente resistentes ao INF isolado, em dois grupos de 24 pacientes cada um, randomizados, que receberam 3 a 6 milhões de INF-alfa 3 vezes por semana mais ribavirina $1000 \mathrm{mg} / \mathrm{dia}$ ou somente INF-alfa, nas mesmas doses, durante 6 meses. Concluíram que os da associação ribavirina/IFN tiveram resposta mais efetiva nos retratamentos do que os restantes, isto quanto aos dados bioquímicos de remissão sustentada. Porém os efeitos colaterais são maiores neste grupo.

POYNARD et al. ${ }^{(39)}$ compararam INF-alfa-2b mais ribavirina com INF mais placebo, durante 24-48 semanas, em 832 pacientes portadores de HVC, randomizados, concluindo que houve resposta virológica persistente (RVP) na $24^{\mathrm{a}}$ semana depois da suspensão do tratamento em $43 \%$ dos pacientes do primeiro grupo, contra $35 \%$ do segundo. No grupo tratado com IFN isolado, a RVP foi de $19 \%$.

REICHARD et al. ${ }^{(41)}$, usando o mesmo esquema anterior em 100 pacientes, encontraram RVP de $46 \%$ versus $22 \%$. Um ano após a 
suspensão do tratamento, a RVP manteve-se em $42 \%$ versus $20 \%$, respectivamente.

SCHALM et al. ${ }^{(43)}$ acreditam poder identificar melhor os pacientes HVC com clareamentos virais mais efetivos após aplicação de INF. Hoje em dia esses níveis de clareamentos persistentes não ultrapassam $20 \%$ dos pacientes. Para tanto, os autores identificaram os genótipos 1 e os trataram com a associação INF/ribavirina, prolongando-o para 12 meses, atingindo, assim, níveis de clareamento viral sustentado em $36 \%$ dos pacientes.

TANAKA et al. ${ }^{(51)}$ usaram ácido ursodeoxicólico (AUC) associado ao INF-alfa, sem bons resultados.

DUSHEIKO et al. ${ }^{(13)}$ usaram ribavirina contra placebo em estudo controlado e não obtiveram resultados significativamente diferentes nos dois grupos, analisando os níveis de HVC RNA e os aspectos histológicos, 6 meses após sua interrupção.

TSUTSUMI et al. ${ }^{(53)}$ usaram ofloxacina $600 \mathrm{mg}$ por dia, durante 12 semanas, associada ao INF-alfa, 6 milhões de unidades 3 vezes por semana, durante 21 semanas. $\mathrm{O}$ grupo com a associação respondeu melhor.

HOOFNAGLE et al. ${ }^{(24)}$ acreditam que a terapia com ribavirina 1000-1200 mg por dia - durante 24 meses, não determina queda dos níveis da viremia e, portanto, deve ser continuada indefinidamente, apesar dos graves efeitos colaterais.

Nos casos de provável associação de HVC e manifestações de autoimunidade ${ }^{(52)}$, refletidas por seus marcadores antinucleares, antimúsculo liso e antifígado/rins antimitocondriais, os autores analisaram três pacientes, com essas raras características, administrando azatioprina - $2 \mathrm{mg} / \mathrm{kg}$ - mais prednisona $1 \mathrm{mg} / \mathrm{kg}$ de peso corporal, durante 2 anos. Os autores acreditam que este tipo de tratamento encontra maior reforço naqueles pacientes que inicialmente não responderam aoINF-alfa, isoladamente.

VILLARRUBIA et al. ${ }^{(55)}$ sugerem quanto ao tratamento das hepatites B e de outras doenças víricas persistentes (HVC), associação de ribamidina (ribavirina 3-carboxamida), droga antiviral, com fungo-imunomodulador "Inmunoferon" (AM3), baseados em modelo experimental hepatotóxico em ratos, na dose de 50 a $150 \mathrm{mg} / \mathrm{kg} / \mathrm{dia}$, por via oral ou subcutânea. A racionalidade do modelo utilizado repousa no fato de que o AM3 restaura a imunidade natural mediante indução da produção de interleucina (IL-12) e do interferon gama. Outrossim, o AM3 diminui o fator C3 do sistema complemento implicado na regulação a menor do IL-12.

Assim sendo, a combinação ribamidina/AM3 evitaria o denominado "caos imunológico" induzido por esses vírus hepatotrópicos. Esse caos imune acontece devido à volta da resposta inflamatória intempestiva, na qual o fator C3 joga papel primordial, bloqueando a produção monocitária do IL-12 e, conseqüentemente, da resposta natural imune celular.
Portanto, o sistema imune dispõe de pelo menos três oportunidades para tentar eliminar os vírus, ou sejam, a resposta inflamatória inespecífica, a natural e a imune específica.

Os novos tratamentos visam reforçar essas oportunidades, restaurando o caos imune, através do uso de antivirais de ação direta (ribavirina, ribamidina, famciclovir, lamivudina e o próprio INF-alfa), associados a imunemoduladores (AM3, timosina, plasmídios DNA), no sentido de criar alternativas terapêuticas válidas, diante de um panorama atual muito desfavorável para os pacientes de hepatites virais, particularmente as do tipo $\mathrm{C}$.

SHERMAN et al. ${ }^{(44)}$, associaram timosina alfa-1 (TA1), peptídio imunomodulador, 1,6 $\mathrm{mg}$ por dia subcutâneo, 2 vezes por semana com INF-alfa-2b 3 vezes por semana, em estudo randomizado, placebo-controlado duplo cego, durante 26 semanas, em 103 pacientes. Ao final, houve $37,1 \%$ de respostas positivas no grupo tratado com a associação, contra $16,2 \%$ no grupo de INF isoladamente e $2,7 \%$ no grupo controle. O clareamento viral ocorreu em 37,1\% no grupo INF/ TA1 e em 18,9\% do grupo INF. Esses autores acreditam que a adição de droga imune estimulante (TA1) ao agente anti-viral (INF-alfa-2b) pode melhorar a resposta final, nesse grupo de pacientes.

FARRELL et al. ${ }^{(16)}$, em estudo internacional randomizadocontrolado, em 1071 pacientes, utilizaram INF linfoblastoide alfa-n1 versus INF recombinante alfa-2b, durante 6 meses, nas mesmas doses de 3 milhões de unidades subcutânea, 3 vezes por semana e obtiveram resultados semelhantes nos dois grupos, sendo que o grupo INF-alfan1 teve resposta sustentada mais elevada, ou seja, 37, 9\% x 35,3\%.

Notar também que o prolongamento do tratamento para 12 meses ou mais, reduz a taxa de recidivas de $50 \%{ }^{(3,28,37)}$, para os dois tipos de INF.

NIEDERAU et al. ${ }^{(32)}$ utilizaram fosfatidil-colina poliinsaturada (PPC) em associação ao INF-alfa-2a ou 2b, em 176 pacientes portadores de HVB ou HVC, na dose de 1,8 g por dia (seis cápsulas), durante 24 semanas e INF 5 milhões de unidades para os $\mathrm{HVB}$ e 3 milhões de unidades para os HVC, três vezes por semana, durante o mesmo período de 24 semanas. Nos pacientes que receberam PPC houve resposta bioquímica boa (queda de $>50 \%$ da ALT) em $71 \%$ dos casos contra 56\% no grupo placebo, nos dois grupos HVB e HVC. Concluem que o PPC deve ser recomendado em associação com o IFN, nos casos de HVC, além do que, sua administração deve ser continuada mesmo após a suspensão do INF, pois assim, reduzem as taxas de recaídas da doença. O PPC é extraído do óleo de soja: Essentiale forte, Rhône Poulenc Rorer $\mathrm{GmbH}$, Cologne, Alemanha, contém lecitina, óleos essenciais de fosfolípides, fosfatidil colina $72-76 \%$. Não se conhecem detalhes quanto aos mecanismos de ação envolvidos fisiopatologicamente nesses pacientes tratados com a associação acima descrita. Não há inibição da replicação viral, nem sobre o clareamento de RNA HVC, talvez haja estabilização da membrana celular hepatocitária, protegendo, assim, o hepatócito contra vários tipos de agressão, viral, alcoólica, entre outras. 
Existem estudos anteriores feitos em baboons que mostraram efeitos protetores do PPC contra a cirrose alcoólica e diminuição da fibrose por diminuição da produção de colágeno estimulada pelo acetaldeído (aumento da atividade da colagenase) ${ }^{(18,27,31,59)}$.

A história natural da HVC modifica-se quando existir co-infeção associada ao vírus da imunodeficiência humana (SIDA), com aceleração (20). Essa co-infeção existe em 7\%-10\% dos pacientes, quando se considera a sero-prevalência, e está condicionada aos modos de contaminação, sendo os toxicômanos intravenosos os de seroprevalência mais elevada ( $50 \%$ a $90 \%$ ), ao lado dos politransfundidos $(60 \% \text { a } 80 \%)^{(40)}$. Essa aceleração na historia natural da doença caracteriza-se por um aumento na taxa de cirroses. Alem disso, nesses pacientes, há maior carga viral e nítida linfopenia CD4 $\operatorname{associada}^{(10)}$. Deve-se ressaltar, ainda, maior ineficácia dos tratamentos antivirais instituídos, quer no sentido das respostas precoces, ou tardias. Assim, quando submetidos aos tratamentos antiretrovirais duplos ou triplos, ou sejam, dois nucleosídios ou dois nucleosídios mais antiprotease, durante 3 meses, não se observam modificações nem na carga viral, nem nos níveis de transaminases no soro desses pacientes.

DIENSTAG $^{(11)}$ acredita, quase 10 anos após uso de INF no tratamento da HVC, que a frustração no meio médico é muito grande, pois as respostas positivas sustentadas não ultrapassam 1:10, dos casos. Em painel multidisciplinar (Consensus Development Conference, março 1997), fixou-se a conduta terapêutica mais adequada a esses pacientes, considerando-se aspectos diagnósticos, da historia natural, epidemiológicos e da prevenção da HVC, ou seja, os candidatos à terapia devem ter ALT elevada, HVC RNA detectável e evidências histológicas de fibrose septal e/ou de hepatite crônica moderada ou grave, ou melhor, sinais presuntivos de progressão da doença. Por outro lado, não recomendam tratamento para pacientes com alterações histológicas leves, cirrose compensada e idades menores de 18 anos e maiores de 60 anos. Idem, para os pacientes com cirrose descompensada e transplantados de fígado. Os pacientes com ALT persistentemente normal, não respondem ao IFN e podem ter reações colaterais desagradáveis, com piora bioquímica apreciável. Recomendam tratamento para as hepatites agudas, pois já foi evidenciado aumento do clareamento viral nesses pacientes. Os índices preditos de possível resposta, como os níveis de HVC RNA ou os genotipos, são inadequados e não devem contraindicar o tratamento com INF. As contra-indicações relativas ao tratamento incluem a síndrome depressiva, citopenia, alcoolismo, uso de drogas, hipertiroidismo, transplante renal e doença auto imune. A dose ótima deve ser de 3 milhões de unidades 3 vezes por semana, durante 12 meses.

Os não-responsivos podem ser identificados ao final de 3 meses de tratamento, verificando-se níveis de ALT e de HVC RNA. Nesses casos identificados, deve-se suspender o tratamento com INF. Em casos de re-tratamento, utiliza-se outro medicamento associado ao INF. As recaídas após 6 meses de tratamento com INF devem sofrer nova terapia com o mesmo INF, agora durante 12 meses, ou então, associar-se ribavirina que, na pior das hipóteses, dobra os índices de resposta positiva sustentada, nesses pacientes.

Assim sendo, SHIFFMAN et al. ${ }^{(46)}$, nos pacientes com viremia ainda positiva aos 6 meses, depois da suspensão do tratamento com INF, portanto nos pacientes não-respondedores porém com alguma melhora histologicamente observada, aconselham o seu prosseguimento por mais 2 anos suplementares, com o intuito de prevenir maior agravamento evolutivo da doença.

ZEUZEM et al. ${ }^{(57)}$, utilizando INF-alfa com ou sem amantadina associada, no tratamento inicial de pacientes "naifs" de hepatite crônica $\mathrm{C}$ não obtiveram melhores resultados do que aqueles obtidos com INF isoladamente, nos mesmos pacientes "virgens" de tratamento, ou sejam, em torno de $10 \%$ de resultados positivos sustentados. Outro recurso terapêutico utilizado nesta abordagem, consiste na utilização de doses diárias de INF, o que permitiu clareamento viral mais precoce, porém com respostas duráveis decepcionantes ${ }^{(45)}$.

A conjugação do INF com o polietilenoglicol (INF peguilado), retarda sua difusão e permite sua aplicação semanal, obtendo-se níveis séricos estáveis e resultados positivos sustentados em $25 \%$ a $39 \%$ versus $5 \%$ a $19 \%$, quando se os comparam com INF standard ${ }^{(58)}$. A associação de INF peguilado com ribavirina está em estudos, sendo seus resultados preliminares promissores quando comparados àqueles obtidos com INF standard, particularmente no tocante ao clareamento viral ${ }^{(50)}$.

O polietilenoglicol INF foi recentemente aprovado pelo Food and Drug Administration (FDA), órgão do governo norte-americano que regula a comercialização de remédios e alimentos, e até o final de 2001 deverá estar sendo vendido no Brasil. Nos EUA sua comercialização deve estar liberada a partir de julho (PegIntron ${ }^{\circledR}$, fabricado pela ScheringPlough). Este novo medicamento, em estudo realizado nos EUA, Canadá e Europa, com 1530 pacientes e apresentado no Encontro Anual da Associação Americana para o Estudo de Doenças do Fígado, ocorrido em Dallas, Texas, EUA, em outubro de 2000, mostrou que o remédio, associado à ribavirina, obteve em $61 \%$ dos pacientes, erradicação viral completa, contra $47 \%$ dela com o tratamento convencional (INF-alfa-2b + ribavirina)

Deve-se ressaltar, ainda, que existem indícios de acentuada redução na recidiva após a interrupção do tratamento com a nova droga ${ }^{(34)}$.

BOOTH et al. ${ }^{(5)}$ recomendam não tratar pacientes com lesões hepáticas mínimas ou leves à histologia; no entanto, propõem revisão a cada 6 meses, com biopsias repetidas a cada 2-3 anos. Em casos de piora, o tratamento deve ser considerado. Usam 3 a 6 milhões de unidades de INF-alfa 3 vezes por semana, durante 6 a 18 meses, sendo as doses maiores e por tempo mais prolongado reservadas para os de maior risco, no mínimo, por um ano. Nos casos de falência do tratamento, aconselham associar ribavirina.

VAN THIEL et al. ${ }^{(54)}$ e OLYNYK et al. ${ }^{(33)}$ demonstraram que os não-respondedores têm valores mais altos de ferro no fígado do que os 
respondedores e que disso resulta maior estado oxidativo dos hepatócitos, com conseqüente aumento da suscetibilidade celular à lesão ou necrose ${ }^{(15)}$. Baseados nestes fatos, CARENI et al. ${ }^{(7)}$ e HAYASHI et al. ${ }^{(21)}$ propuseram combinar flebotomia com IFN, obtendo assim, maior redução da atividade das transaminases, maior número de pacientes PCR negativos e diminuição das recaídas após o tratamento. O estado oxidativo maior dos hepatócitos é importante e indicaria teoricamente o uso de $\mathrm{N}$-acetylcisteína, poderoso antioxidante ${ }^{(5)}$.

HOOFNAGLE ${ }^{(25)}$ acredita que passados 3 anos do consenso de 1977, dois quesitos merecem comentários e talvez modificações, ou seja, que a genotipagem do HVC não é útil clinicamente e que o regime ótimo de tratamento seja o de 12 meses com INF-alfa, associado ao teste de controle aos 90 dias depois do seu início. Em caso de viremia ainda positiva, o tratamento deve ser suspenso. O mesmo autor admite que essas modificações decorreram mais dos melhores resultados obtidos com a associação recentemente utilizada do INF à ribavirina, ou sejam, altos índices de respostas positivas sustentadas quando comparadas aos obtidos com INF isolado. A genotipagem do HVC seria importante apenas para se determinar o tempo ótimo de duração do tratamento, pois está bem demonstrado que nos pacientes G2 e G3 esses índices são de 67\% e 64\%, respectivamente, aos 6 e 12 meses de tratamento. Nos pacientes G1, os mesmos índices foram significativamente mais baixos quer aos 6 (16\%), quer aos 12 meses (28\%). Portanto, concluem que nos últimos, o tratamento deva ser de 1 ano e nos dois primeiros de 6 meses. Em relação aos pacientes G1 com baixos níveis de HVC RNA ou então, já previamente tratados com respostas transitórias e recaídas, não existe ainda consenso entre 6 e 12 meses de tratamento para a obtenção de resultados benéficos adicionais. No entanto, nos casos de RNA ainda positivos, aos 6 meses, deve-se suspender o tratamento.

HEZODE e DHUMEAUX ${ }^{(22)}$ acreditam que a decisão de se iniciar ou não o tratamento nos pacientes cronicamente infectados pelo HVC, depende de vários parâmetros. Os mais importantes seriam o grau de atividade da doença, a idade e o estado geral dos pacientes, as chances de resposta e as contra-indicações ao tratamento. Para eles somente os pacientes com atividade histológica METAVIR A maior ou igual a 2 e/ou F maior ou igual a 2 devem ser tratados. Os de atividade histológica mínima têm risco evolutivo pequeno e os possíveis benefícios advindos do tratamento ainda não foram demonstrados. É o caso dos pacientes com aminotransferases repetidamente normais. Por outro lado, a cirrose diminui muito as chances de sucesso do tratamento, porém não o contra-indica. Os cirróticos ativos devem ser tratados, os inativos suscitam dúvidas. Haveria redução dos riscos de desenvolvimento de carcinoma hepatocelular, particularmente nos pacientes mais jovens? Mais do que a idade cronológica importaria a fisiológica e o estado cardiovascular, particularmente quando se pretender usar a ribavirina nesse esquema terapêutico.
Os genotipos e a carga viral são os dois fatores mais importantes ligados à resposta ao tratamento combinado $\mathrm{INF} /$ ribavirina, no entanto, respostas sustentadas são possíveis quaisquer que sejam seus perfis e, na maioria das vezes, a decisão do tratamento não os levam em consideração.

Quanto aos pacientes virgens de tratamento ("naifs") a associação INF/ribavirina mostrou-se nitidamente superior ao INF isolado, sendo a resposta durável sustentada após 6 meses de interrupção, de $41 \%$ versus $16 \%$, respectivamente.

Nos pacientes G2 e G3, com qualquer carga viral, essa resposta foi de $65 \%$ versus $35 \%$ dos G1 com carga viral pequena (menor do que $2.10^{5}$ copias $/ \mathrm{mL}$ ), sendo que esses percentuais não melhoraram com o prolongamento do tratamento além dos 6 meses. Fazem exceção os $\mathrm{G} 1$ com carga viral maior do que $2.10^{5}$ copias $/ \mathrm{mL}$, cujas respostas após um ano de tratamento chegam a $28 \%$ versus $8 \%$, aos 6 meses. Esses resultados, fizeram com que o Consenso International sobre HVC, em fevereiro de $1999^{(14)}$, recomendasse o tratamento combinado durante 6 meses para os pacientes "naifs" e de 12 meses para os G1 com carga viral elevada. Naquela ocasião, as unidades de quantificação do ARN do VHC não estavam estandardizadas. Hoje se admite como níveis de decisão $800.000 \mathrm{UI} / \mathrm{mL}^{(22)}$.

As esperanças depositadas no desenvolvimento de vacinas efetivas estão sendo enfraquecidas por dois aspectos inerentes ao próprio vírus $\mathrm{C}$ e a sua reconhecida mutabilidade e a infecção persistente, na maioria dos pacientes, apesar das respostas imunes humoral e celular verificadas. Por outro lado, é encorajado o fato da maior resposta proliferativa de CD4 nos pacientes com evolução mais benigna ${ }^{(6)}$ e melhor resposta ao $\mathrm{INF}^{(23)}$. Essas vacinas incluem vírus mortos, vírus atenuados, proteínas recombinantes, injeção de DNA e de vectores de DNA. As duas primeiras são inseguras, as restantes promissoras e passíveis de uso na prática médica, visando reforçar o braço celular do sistema imune, como terapia vacinal futura não muito distante, $\operatorname{esperamos}^{(8)}$.

\section{COMENTÁRIOS FINAIS}

Atualmente a hepatite crônica $\mathrm{C}$ é a principal causa de hepatopatias crônicas, cirroses e carcinoma hepatocelular. No Consenso de 1977, houve importantes avanços e conclusões quanto ao diagnóstico, avaliação, prevenção e tratamento da doença. Essas conclusões foram largamente aceitas e trouxeram certa uniformidade no manuseio da afecção. No entanto, face a rápida evolução de conceitos havidos, nestes últimos 3 anos, tornou-se tarefa difícil mantê-los vigentes. Assim, dois deles merecem modificações, ou sejam, a utilidade clínica da genotipagem do VHC e o regime terapêutico considerado ótimo.

Os vários trabalhos feitos têm demonstrado que a combinação INF/ ribavirina forneceu os mais altos graus de resposta positiva sustentada, comparativamente ao uso do INF isoladamente. E que o regime terapêutico ótimo é o de 24 semanas para os genotipos 2 e 3 e o de 48 
semanas para os G1. Além disso, ficou bem patente que a terapia deve ser suspensa, na $24^{\text {a }}$ semana, caso o HVC RNA ainda esteja presente.

O uso do INF-alfa isoladamente deve ser reservado para os pacientes com formais contra-indicações à ribavirina, como anemia, insuficiência renal, doença cerebral e cardiovascular, gravidez, entre outras.

No entanto, ainda permanecem vários desafios clínicos, como por exemplo, a avaliação correta do grau e do estágio evolutivo da doença frente ao tratamento instituído e à completa eliminação do agente viral da circulação e do tecido hepático, aumentar os índices de resposta sustentada, diminuir os efeitos colaterais dos tratamentos usuais e diminuir os custos financeiro e social da população doente.

Define-se como recaída a volta do HVC RNA 6 meses após a interrupção do tratamento, nos pacientes não-reativos. No entanto, sabe-se que estas recaídas podem ocorrer até 12 meses depois, em cerca de $20 \%$ dos pacientes. Por outro lado, não existem ainda marcadores confiáveis que possam fazer essa previsão. Seria, então, necessário um super-sensível marcador PCR HVC RNA que demonstrasse acuradamente a erradicação completa do vírus.

Outros marcadores serológicos como os anti-E2, ou marcadores imunológicos NS3, seriam úteis para detectar replicações virais de baixo nível.

Os efeitos adversos dos tratamentos combinados (INF/ribavirina), de 1 ano de duração, podem ser minorados, baixando-se as doses de cada um deles.

Nos grupos especiais de pacientes existem outros desafios a serem considerados. Assim, nas crianças e nos velhos ainda são desconhecidos os índices de resposta e a segurança da terapia usual. Idem, nas coinfecções com HIV, nos alcoolistas e/ou drogaditos, nas doenças neurológicas e psiquiátricas, nas autoimunepatias, insuficiência renal, hemofilia, talassemia, transplantados, entre outros. Nas hepatites $\mathrm{C}$ agudas, nas formas crônicas moderadas, nos pacientes com aminotransferases normais e nos cirróticos descompensados, também não se conhece a eficácia e a segurança dos tratamentos usuais. Idem, nas crioglobulinemias ou glomerulonefrites associadas ao VHC, em particular quando se utiliza o INF associado a outros medicamentos. Nos casos de exposição acidental ao VHC, como por exemplo, nas picadas por agulhas, o que fazer? Tratar preventivamente, aguardar a positivação do HVC RNA, esperar as manifestações clínicas da doença ou procurar evidências de doença crônica? E nos indigentes, nos sem tetos, nos presidiários, nas instituições públicas e entre outros grupos populacionais especiais, o que fazer? A decisão de iniciar-se ou não o tratamento nos pacientes infectados pelo HVC baseia-se em vários parâmetros, sendo os mais importantes o grau de atividade da doença (que condiciona sua evolução), a idade e o estado geral do paciente, as chances de resposta ao tratamento e suas eventuais contra-indicações.

A primeira é obtida a partir do exame histológico do fígado, indispensável antes do tratamento ser ou não iniciado. Somente os portadores de atividade e/ou fibrose moderada ou grave serão candidatos ao tratamento.

Os pacientes com lesões histológicas mínimas têm risco evolutivo muito pequeno e os benefícios de um possível tratamento não foram ainda demonstrados. Aqueles com atividade sérica de aminotransferases repetidamente normal serão tratados apenas seguindo-se protocolos pré-estabelecidos. A existência de cirrose diminuí bastante as chances de sucesso terapêutico, porém não o contra-indica formalmente. Os cirróticos em atividade devem ser tratados. O interesse do tratamento dos inativos repousa no risco de diminuir a incidência de carcinoma hepatocelular e é ainda motivo de discussão. Existe alguma lógica em admitir-se algum tipo de tratamento nos pacientes mais jovens, independentemente da idade de início desse mesmo tratamento, respeitando-se mais a idade fisiológica do que a cronológica, particularmente o estado cardiovascular deles, quando se pretender utilizar a ribavirina.

Quanto à genotipagem do $\mathrm{VHC}$ e a sua carga viral diga-se que não são levadas em conta, no sentido da decisão do tratamento, mas sim, no sentido da avaliação da resposta duradoura ou não. As pesquisas em curso quanto ao desenvolvimento de novos recursos terapêuticos como o de moléculas inibidoras especificas de certas enzimas virais (proteases, helicases, polimerases), ou de certas funções virais (oligonucleotídios, ribozima), podem inibir a replicação viral, na grande maioria dos infectados e serem usados isoladamente ou em associação com o INFalfa. Outros agentes bloqueadores da replicação viral, como o IRKS ("internal ribosomal entry site") e o receptor da superfície celular do HVC, têm sido estudados. Idem, os moduladores da citoquina e as próprias citoquinas que podem afetar o ciclo vital do VHC, também têm sido consideradas e representam esperanças futuras promissoras.

A infecção HVC persistente e a lesão celular concomitante são fortemente influenciadas por mecanismos imunes, donde os imunemoduladores ou imunestimulantes poderem eventualmente ser efetivos nesse tratamento.

Os agentes citoprotetores não-específicos também podem atuar no interior dos hepatócitos, favorecendo processos reparativos celulares.

Não se sabe como atua a ribavirina aumentando a ação anti-viral do INF. Poderia ser inibidora direta da replicação vital, interferindo com a RNA polimerase, ou modulando a resposta imune por meio do balanceamento Th1 /Th2 da resposta celular, ou ainda, por citoproteção direta. 
Conte VP. Hepatitis C virus. Part 2. Therapy. Arq Gastroenterol 2000;37(4):235-242.

ABSTRACT - Several aspects are revised on the subject related to drugs used, their doses, duration of treatment, different responses obtained, according diferent types of diseases and patients studied, as the factors able to modify the results obtained.

HEADINGS - Hepatitis C, therapy. Interferon. Ribavirin. Amantadin. Vaccines.

\section{REFERÊNCIAS BIBLIOGRÁFICAS}

1. Alter MJ. Epidemiology of hepatitis C in the West. Semin Liver Dis 1995;15:5-14.

2. Bellobuono A, Mondazzi L, Tempini S, Silini E, Vicari F, Ideo G. Ribavirin and interferon-alpha combination therapy vs interferon-alpha alone in the retreatment of chronic hepatitis C: a randomized clinical trial. J Viral Hepat 1997;4:185-91.

3. Benhamou J, Hopf U, Rizzetto M. A randomised, double-blind, controlled muiticentre study of human lymphoblastoid interferon alfa in the treatment of adults with chronic hepatitis non-A non-B [abstract]. J Hepatol 1995;23:173A.

4. Bodenheimer HC Jr, Lindsay KL, Davis GL, Lewis JH, Thung SN, Seeff LB. Tolerance and efficacy of oral ribavirin treatment of chronic hepatitis C: a multicenter trial. Hepatology 1997;26:473-7.

5. Booth JCL, Brown JL, Thomas HC. The management of chronic hepatitis $\mathrm{C}$ virus infection. Gut 1995;37:449-54.

6. Botarelli P, Brunetto MR, Minutello MA, Calvo P, Unutmaz D, Weiner AJ, Choo QL, Shuster JR, Kuo G, Bonino F. T-lymphocyte response to hepatitis C virus in different clinical course of infection. Gastroenterology 1993;104:580-7.

7. Careni P, Fagiuoli S, Van Thiel D. Iron reduction therapy: simply camoflage, or a real weapon? Am J Gastroenterol 1995;89:970-3.

8. Choo QL, Kuo G, Ralston R, Weiner A, Chien D, Van Nest G, Han J, Berger K, Thudium K, Kuo C. Vaccination of chipanzees against infection by the hepatitis C virus. Proc Natl Acad Sci U S A 1994;9:1294-8.

9. Chung YH, Shong YK. Development of thyroid auto immunity after administration of recombinant human interferon-alpha-2b for chronic viral hepatitis. Am J Gastroenterol 1994;88:244-7.

10. Cribier B, Rey D, Schmitt C, Lang JM, Kirn A, Stoll-Keller F. High hepatitis C viraemia and impaired antibody response in patients coinfected with HIV. AIDS 1995;9:1131-6.

11. Dienstag JL, editor. Management of chronic hepatitis C: a consensus. Gastroenterology 1997;113:375.

12. Dorr RT. Interferon alfa in malignant and viral diseases. A review. Drugs 1993;45:177-211.

13. Dusheiko G, Main J, Thomas H, Reichard O, Lee C, Dhillon A, Rassam S, Fryden A, Reesink H, Bassendine M, Norkrans G, Cuypers T, Lelie N, Telfer P, Watson J, Weegink C, Sillikens P, Weiland O. Ribavirin treatment for patients with chronic hepatitis C: results of a placebo-controlled study. J Hepatol 1996;25:591-8.

14. EASL. International Consensus Conference on Hepatitis C. Consensus statement. J Hepatol 1999;30:956-61.

15. Farinati F, Cardin R, De Maria N, Della Libera G, Marafin C, Lecis E, Burra P, Floreani A, Cecchetto A, Naccarato R. Iron storage, lipid peroxidation, and glutathione turnover in chronic anti-HCV positive hepatitis. J Hepatol 1995;22:449-56.

16. Farrell CF, Bacon BR, Goldin RD, The Clinical Advisory Group for the HVC Comparative Study. Lymphoblastoid interferon alfa-n1 improves the long-term response to a 6-month Course of Treatment in Chronic Hepatitis C compared with recombinant interferon alfa-2b: results of an lntemational Randomised Controlled Trial. Hepatotogy 1998;27:1121-7.

17. Findor JA, Silva M, Medina M, Bruch Igartua E, Sorda J, Findor AJ, Schiff E. Prevalencia de anticuerpos anti virus de la hepatitis C (anti HCV) en diferentes poblaciones de hepatopatias cronicos con una prueba de primera generacion. Acta Gastroenterol Latinoam 1991;21:221-5.

18. Fuji S, Okuda T, Imagawa T. Effect of poiyphosphatidyl-choline (PPC) on experimentally induced liver disturbances. Shikoku Acta Med 1974;30:76-85.

19. Garassini M, Ortega F, Valdes A, Alvarado M, Cid A, Serrano L, Torres G, Hagen E, Dugarte I, Perez N. Anticuerpos contra el virus de la hepatitis C en pacientes con hepatopatias y en sujetos a riesgo. Comunicacion preliminar. GEN 1990;44:343-8.
20. Gavazzi G, Richallet G, Morand P, Bouchard O, Bosseray A, Leclercq P, Micoud M. Effects des bi- et trithérapies antirétrovirales sur les charges virales VHC chez les patients coinfectés par le VIH et le VHC. Pathol Biol (Paris) 1998;46:412-5.

21. Hayashi H, Takikawa N, Nishimura N, Yano M, Isomura T, Sakamoto N lmprovement of serum aminotransferase levels after phlebotomy in patients with chronic active hepatitis $\mathrm{C}$ and excess hepatic iron. Am J Gastroenterol 1995;89:986-8.

22. Hezode Chi, Dhumeaux D. Traitment de l'hepatite chronique virale C: present et futur proche. Gastroenterol Clin Biol 2000;24:533-5.

23. Hoffmann RM, Diepolder HM, Zachovel R, Zwiebel FM, Jung MC, Scholz S, Nitschko H, Riethmuller G, Pape GR. Mapping of immunodominant CD4 ${ }^{+}$T lymphocyte epitopes of hepatitis $\mathrm{C}$ virus antigens and their relevance during the course of chronic infection. Hepatology 1995;21:632-8.

24. Hoofnagle JH, Lau D, Conjeevaram H, Kleiner D, Di Bisceglie AM. Prolonged therapy of chronic hepatitis C with ribavirin. J Viral Hepat 1996;3:247-52.

25. Hoofnagle JH. Management of hepatitis C: current and future perspectives. J Hepatol 1999;31 (Suppl 1):264-8.

26. Kiyosawa K, Sodeyama TE, Tanaka E. Interrelationship of blood transfusion, non-A non-B hepatitis and hepatocelular carcinoma: analysis by detection of antibody to hepatitis C virus. Hepatology 1990;12:671-5.

27. Lieber CS, Robins SJ, Li J, DeCarli LM, Mak KM, Fasulo JM, Leo MA. Phosphatidylcholine protects against fibrosis and cirrhosis in the baboon. Gastroenterology 1994;106:152-9.

28. Lin R, Roach E, Zimmerman M, Strasser S, Farrell GC. Interferon alfa-2b for chronic hepatitis C: effects of dose increment and duration of treatment on response rates. Results of the first multicentre Australian trial. J Hepatol 1995;23:487-96.

29. Mattson L, Sonnerberg A, Weiland O. Outcome of acute symptomatic non-A non-B hepatitis: a 13-year follow-up study of hepatitis $\mathrm{C}$ vírus markers. Liver 1993;13:274-8.

30. Milella M. Neutralizing antibodies to recombinant alpha-interferon and response to therapy in chronic hepatitis C virus infection. Liver 1993;13:146-50.

31. Neuberger J, Hegarty JE, Eddleston AL William R. Effect of polyunsatured phosphatidylcholine on immune mediated hepatocyte damage. Gut 1983;24:751-5.

32. Niederau C, Strohmeyer G, Heintges T, Peter K, Gopfert E. Polyunsatured phosphatidyl-choline and interferon alpha for treatment of chronic hepatitis B and C: a multi-center, randomised, double-blind placebo-controlled trial. Leich Study Group. Hepatogastroenterology 1998;45:797-804.

33. Olynyk JK, Reddy KR, Di Bisceglie AM, Jeffers LJ, Parker TI, Radick JL, Schiff $\mathrm{ER}$, Bacon BR. Hepatic iron concentration as a predictor of response to interferon alfa therapy in chronic hepatitis C. Gastroenterology 1995;108:1104-9.

34. Parise ER, Cançado ELR, Cheinquer H, Silva LC da, Ferraz ML, Paraná R. Tratamento da hepatite crônica pelo vírus C. GED Gastroenterol Endosc Dig 2000;19:203-7

35. Peters M. Mechanism of action of interferon. Semin Liver Dis 1989;9:235-9.

36. Polachon M. Intérêt de l'interferon alpha à forte dose chez les malades atteints d'une HVC chronic que non respondeurs à un premier traitment. Gastroenterol Clin Biol 1997;21:924-8.

37. Poynard T, Bedossa P, Chevallier M. A comparison of three interferon alfa- $2 b$ regimens for the long-term treatment of chronic non-A non-B hepatitis. N EngI J Med 1995;332:1457-62.

38. Poynard T, Leroy V, Cohard M, Thevenot T, Mathurin P, Opolon P, Zarski JP. Meta-analysis of interferon randomized trials in the treatment of viral hepatitis C: effect of dose and duration. Hepatology 1996;24:778-89.

39. Poynard T, Marcellin P, Lee SS, Niederau C, Mikuk GS, Ideo G, Bain V, Heathcote J, Zeuzem S, Trepo C, Albrecht J. Randomised trial of interferon alpha $2 b$ plus ribavirin for 48 weeks or 24 weeks versus interferon alpha $2 \mathrm{~b}$ plus placebo for 48 weeks for treatment of chronic infection with hepatitis $\mathrm{C}$ virus. Lancet 1998;352:1426-32. 
40. Quan CM, Kradjen M, Grigoriew GA, Salit IE. Hepatitis C virus infection in patients infected with the human immunodeficiency virus. Clin lnfect Dis 1993; 17:117-9.

41. Reichard O, Nortrans G, Frydén A. Randomised, double-blind, placebocontrolled trial of interferon alfa- $2 \mathrm{~b}$ with or without ribavirin for chronic hepatitis C. Lancet 1998;351:83-7.

42. Renault PF, Hoofnagle JH. Side effects of alpha interferon. Semin Liver Dis 1989;9:273-7.

43. Schalm SW, Brouwer JT. Antiviral therapy of hepatitis C. Scand J Gastroenterol 1997 (Suppl 223):46-9.

44. Sherman KE; Sjogren M, Creager RL, Damiano MA, Freeman S, Lewey S, Davis D, Root S, Weber FL, Ishak KG, Goodman ZD. Combination therapy with thymosin alfa 1 and interferon for the treatment of chronic hepatitis $\mathrm{C}$ infection: a randomized, placebo-controlled double-blind trial. Hepatology 1998; 27:1128-35.

45. Shiffman ML. Use of high-dose interferon in the treatment of chronic hepatitis C. Semin Liver Dis 1999;19(Suppl 1):25-33

46. Shiffman ML, Hofmann CM, Contos MI, Luketic VA, Sanyal AJ, Sterling RK. A randomized controlled trial of maintenance interferon therapy for patients with chronic hepatitis $\mathrm{C}$ virus and persistent viremia. Gastroenterology 1999;117:1164-72.

47. Silva HC, Munoz GG, Sanchez HG. Anticuerpos anti-virus C de la hepatitis en enfermedad hepatica cronica no alcoholica. Rev Med Chile 1993;121:148-51.

48. Silva LC, Ono KS. Interferon in viral liver diseases: pharmacological aspects. Rev Hosp Clin Fac Med São Paulo 1996;51:211-6.

49. Smith JP. Treatment of chronic hepatitis C with amantadine. Dig Dis Sci 1997;42:1681-7.

50. Sulkowski M, Reindollar R, Yu J. Combination therapy with peginterferon (-2a Peg-Inf) and ribavirin the treatment of patients with chronic hepatitis $\mathrm{C}$ phase II open-label study [abstract]. Hepatology 1999;3O:197A.

51. Tanaka K, Kondo M, Sakaguchi T, Saito S, Arata S, Ikeda M, Kitamura T, Morimoto $\mathrm{M}$, Sekihara H. Efficacy of ursodeoxycholic acid in combination with interferonalpha in treating chronic hepatitis C: results of a long-term follow-up trial. J Gastroenterol Hepatol 1996;11:1155-60.
52. Tran A, Benzaken S, Yang G, Schneider S, Doglio A, Rampal A, Rampal P. Chronic hepatitis $\mathrm{C}$ and autoimmunity: good response to immunosuppressive treatment. Dig Dis Sci 1997;42:778-80.

53. Tsutsumi M, Takada A, Takase S, Sawada M. Effects of combination therapy with interferon and ofloxacin on chronic type $\mathrm{C}$ hepatitis: a pilot study. J Gastroenterol Hepatol 1996;11:1006-11

54. Van Thiel DH, Friedlander L, Fagiuoli S, Wright HI, Irish W, Gavaler JS. Response to interferon alpha is influenced by lhe iron content of lhe Iiver. J Hepatol 1994;20:410-5.

55. Villarrubia VG, Herrerias JM, Álvarez-Mon M, Chirigos MA. Virus de la hepatitis B y la respuesta inflamatoria/inmunológica(II): una nueva oportunidad de tratamiento de ia infeccion cronica y una sugerencia para el tratamiento de otras enfermedades viricas persistentes. Rev Esp Enferm Dig 1998;90:514-22.

56. Yano M, Kumada H, Kage M. The long-term pathological evolution of chronic hepatitis C. Hepatology 1996;23:1334-40.

57. Zeuzem S, Tenber G, Nauman V, Berg T, Raedle J, Hartmann S. Randomised, double-blind, placebo-controlled trial of interferon-alfa with or without amantadine as initial treatment for chronic hepatitis C [abstract]. Hepatology 1999;30:200A.

58. Zeuzem S, Feinman SW, Rosenack J, Heahcote EJ, Lai MY, Gane E. Evaluation of the safety and efficacy of one-weekly PEG/interferon alfa-2a (Pegasus*) for chronic hepatitis C. A multinational randomized study [abstract]. J Hepatol 2000;32(Suppl 2):29.

59. Zierenberg O, Grundy SM. Intestinal absorption of polyenylphosphatidylcholine in man. J Lipid Res 1982;23:1136-42.
Recebido para publicação em 2/3/1999. Aprovado para publicação em 22/7/1999. Atualizado em 11/9/2000. 